\title{
A Quality Chinese-English Bilingual Education Program: Defining Success
}

\author{
Liping Wei \\ School of Education, Health Professions, and Human Development, University of Houston-Victoria, TX, USA
}

\begin{abstract}
This study aims to provide an in-depth case study of a Chinese-English bilingual program in the largest ISD of a Southwestern state, in the hope of shedding light on what makes a bilingual education program successful. Few research studies have systematically delved into an English-Chinese bilingual program as this one. The study illuminates that children in this immersion program have benefited from "additive bilingualism" in that they have learned a second language at no cost to their first language and also out-scored their non-immersion peers in state standardized exams. Employing qualitative methods, narrative inquiry in particular, this research study offers a compelling case that bilingual education does not hinder students' English language acquisition. Instead, it accelerates students' English proficiency development while promoting students' second language acquisition, overall academic achievements, and sociocultural integration.
\end{abstract}

Index Terms —Chinese-English, bilingual program, second language development, academic achievements

\section{INTRODUCTION}

This study aims to provide an in-depth case study of a Chinese-English bilingual program in the largest ISD of a Southwestern state, and the 7th largest school district in the U.S, in the hope of shedding light on what makes a bilingual education program successful. This school is the first $100 \%$ dedicated Mandarin language immersion school in this state. It is a two-way immersion or dual language immersion — strong additive bilingual education program, with bilingualism and biliteracy as the aim for the students.

Data from the Center for Applied Linguistics (CAL) suggest that immersion education has been steadily increasing in the United States since the 1970s. However, language education in general is actually declining across the country, especially in the lower grades (Freemark \& Smith, 2014). "The number of American students who learned a language other than English decreased by about 100,000 between 2009 and 2013, according to research by the Modern Language Association" (Noack, 2015). The majority of the studies on bilingual education examined elementary Spanish-English programs; there is not much research on Chinese-English bilingual education. This study intends to add to this body of research by unpacking this particular Chinese-English bilingual program, grounded in Cummins' argument that " $(\mathrm{t}) \mathrm{he}$ accumulation of such case studies presents a rich and robust picture of bilingual education that can benefit practice and influence policy (Cummins, 1999, p. 8)." It is hoped that it will make the educational efficacy of bilingual/immersion programs clearer to a wider policy and public audience.

\section{BACKGROUND OF THE SCHOOL}

When opened in August 2012, this school served only grades PK-2. Since then, it has gone up to a grade level each year in the past five years, and is currently serving students from PK through the $7^{\text {th }}$ grade. This school is a magnet school, which means, unlike regular public schools where students are zoned to, the parents at this school need to apply for the limited spots. Students in the prekindergarten and kindergarten grade levels are not required to have previous experiences with Chinese. Those entering the 1st grade and above must demonstrate proficiency in Chinese as evaluated by the teachers to be included in the lottery process due to the limited availability. Since it opened, this school has become one of the district's most popular magnet programs, with more than eight applications for every available spot. With a $\$ 32.2$ million fund appropriated by the district, a brand-new building and campus were completed in Aug 2016 that allows the school to fulfill its ultimate goal of developing into a well-rounded middle school immersion program in the coming years. As stated on the school website, its vision is "to immerse students in a culture-rich environment that allows them to become balanced bi-cultural and bi-literate citizens for the global economy."

As illustrated in Table 1, the school has a highly diverse student population. Asian take up almost $1 / 3$ of the student body, and African American, Hispanic, and White students each constitute approximately 1/4 of the student population. The school was ranked on the Public School Review "Most Diverse Schools in the U.S." 
TABLE 1

\begin{tabular}{|c|c|c|c|}
\hline \multicolumn{4}{|c|}{ STUDENT INFORMATION (2015-2016 SCHOOL YEAR) } \\
\hline Attendance Rate (2014-15) & $97.2 \%$ & $95.6 \%$ & $95.7 \%$ \\
\hline \multicolumn{4}{|l|}{ Enrollment by Race/Ethnicity } \\
\hline \multicolumn{4}{|l|}{ African American } \\
\hline African American & $17.9 \%$ & $24.4 \%$ & $12.6 \%$ \\
\hline Hispanic & $18.3 \%$ & $62.0 \%$ & $52.2 \%$ \\
\hline White & $20.6 \%$ & $8.5 \%$ & $28.5 \%$ \\
\hline American Indian & $0.0 \%$ & $0.2 \%$ & $0.4 \%$ \\
\hline Asian & $34.5 \%$ & $3.7 \%$ & $4.0 \%$ \\
\hline Pacific Islander & $0.0 \%$ & $0.1 \%$ & $0.1 \%$ \\
\hline Two or More Races & $8.7 \%$ & $1.0 \%$ & $2.1 \%$ \\
\hline \multicolumn{4}{|c|}{ Enrollment by Student Group } \\
\hline \multicolumn{4}{|c|}{ Economically Disadvantaged } \\
\hline Economically Disadvantaged & $21.5 \%$ & $76.5 \%$ & $59.0 \%$ \\
\hline English Language Learners & $16.8 \%$ & $30.3 \%$ & $18.5 \%$ \\
\hline Special Education & $2.3 \%$ & $7.2 \%$ & $8.6 \%$ \\
\hline
\end{tabular}

To some extent, this school is a two-way bilingual program. Though the numbers of the students speaking the two languages are not equal, both Chinese-speaking and English-speaking students serve as "models" in their first language for their counterparts. On the other hand, this school is also a foreign language immersion program. If we look at the percentage of the English Language Learners (ELLs) (See Table 1), only $16.8 \%$ of students speak English as a $2^{\text {nd }}$ language, which means most of the students are from the language majority population. They are placed in content-area classes in this program in which a foreign language - Chinese - is the medium for communication and instruction.

\section{LITERATURE REVIEW}

There are different bilingual education models that exist: transitional bilingual education programs, maintenance bilingual education programs, dual language programs, foreign language immersion programs, and heritage language programs. The most commonly found in the field today is early-exit, transitional model in which students receive instruction in their mother tongue for only two or three years and then transition to English-only instruction with the expectation of being completely adjusted to the mainstream classrooms. When comparing the various bilingual program models, the dual/two-way bilingual education is deemed most effective. The next most effective is one-way, late-exit maintenance model. Less effective are transitional one-way programs.

"Dual language models have grown in popularity with increases in federal support and the growing demand of ELLs' parents and parents of monolingual English speakers who want their children to be bilingual" (Wright, 2015, p. 102). The students who enroll in dual bilingual programs include language minority students who are learning English, and language majority students who already speak English but who want to learn a foreign language. In most cases, these programs are voluntary and require parental permission.

"Student and community demographics have led to innovative variations in dual language programs" (Wright, 2015, p. 102). Whereas the original dual language model seeks equal numbers of ELLs and native English speakers, more and more dual language programs have unequal distribution of native and non-native English speakers, and students from various linguistic, ethnic, and cultural backgrounds, as in the program under study. Unlike in ESL classes where the goal is to prepare students to function effectively in mainstream content-area classes, the goal of two-way bilingual programs is developing proficiency and literacy in both languages. When comparing students in the two-way bilingual program with students in ESL without bilingual education program, controlling for ethnicity, gender, socioeconomic status, grade level, and the differences in pretest scores, researchers found that students in the two-way bilingual program did significantly better at all levels tested (Richard-Amato, 2010).

The foreign language immersion program model was developed in Canada, where native English speakers were immersed for language and content-area instruction in French. Extensive research has demonstrated the effectiveness of these programs. "In the United States, the bilingual immersion model is commonly implemented with English speakers wishing to learn a high-demand world language" (Wright, 2015, p. 103), and are most commonly found in elementary schools and usually last up to 5th or 6th grade. "In foreign language immersion programs, the new language is additive and generally has the support of the parents and the community" (Richard-Amato, 2010, p. 419). According to RichardAmato, a major difference between a foreign language immersion program and a second language immersion program is that in second language immersion programs non-English-native students are considered part of the non-dominant groups in the community, even though their numbers may be greater than those of the dominant group, whereas in foreign language programs all students, regardless of their background, are placed on a pretty much equal footing.

Over the last few decades, research studies have constantly demonstrated that the students achieving bilingualism and biliteracy are more likely to achieve educational success. Those losing one language or replacing one language with another language tend to exhibit far lower level of educational success over time. In spite of the clearly and consistently articulated benefits of bilingual education, its value continues to be overlooked in the wider public domains.

The high-stakes testing policies that attach great importance to English language achievement are damaging to bilingual programs. Knowing that children must soon be assessed in English, "the pressure is growing to phase out 
bilingual instruction as rapidly as possible, before children become fully bilingual and biliterate" (Tinajero, 2005, p. 18) "As a result of this pressure, more and more districts across the country are eliminating native-language instruction in the false hope that this will speed up English acquisition" (Tinajero, 2005, p. 18).

Nevertheless, Tinajero (2005) also pointed out that "while rancorous political debates are raging elsewhere, with confusing claims and counterclaims about the value of bilingual education, Texas is poised to be the model, a paradigm of what is possible when children's cultural and linguistic diversity are treated as the assets they are" (p. 17). Situated in such historical and contextual backdrop, this study intends to provide an in-depth case study of a successful ChineseEnglish bilingual education program in order to deliver a message that compels the public to listen: "Being proficient in two or more languages is now and always will be a tremendous advantage to successful members of our society" (Richard-Amato, 2010, p. 428).

\section{Methodology}

\section{Narrative inquiry}

This research employs narrative inquiry as the methodology, which uses stories as the portal through which human experience is interpreted and made meaningful both individually and socially. Reduced to its essence, narrative inquiry is "the study of experience as story" (Clandinin, Pushor, \& Orr, 2007, p. 22), which is also termed as a "personal experience method" (Clandinin \&Connelly, 1994). Most of the research studies on bilingual education programs either compared with English-only programs or evaluated particular types of bilingual programs, including little or no narrative account of the program that explores the complex, lived experiences of the educators involved in them, as an important angle to examine the effectiveness bilingual education. Utilizing narrative inquiry allows a greater potential of presenting an in-depth case study providing a more complete and thorough profile of a Chinese-English bilingual program in context.

\section{Data Collection}

The participants of the study include Mr. Chuang, the school Principal, and Mr. Reid, Assistant Principal. Each participant took part in an interview based on an interview protocol, which lasted approximately 1 hour. The interview time and location were determined according to the participants' preferences. Both interviews were audiotaped and transcribed verbatim with the participants' written consents, and the transcripts constitute an important source of the data. Other types of data include informal communications with the participants, thick piles of school observation fieldnotes, and a large number of documents accessed from school and district websites.

\section{Data Analysis}

Three analytical tools characterized by narrative inquiry-broadening, burrowing and storying and restorying (Connelly \& Clandinin, 1990) — were used for "narratively cod(ing)" the "lived stories" of the participants. During this process, the "internal and existential conditions" simultaneously inherent in the experience of the participants were paid special attention to, which will be reflected in four directions according to Clandinin and Connelly (1994, p. 417). These directions include inward, which means the internal conditions of participants' feelings, hopes, aesthetic reactions, moral dispositions; outward, which means the existential conditions, the environment, or reality the participants are situated in; backward and forward, which means seeing stories occurring in an ever changing life space in the past, present, and future (See Clandinin \& Connelly, 1994, p. 417). Finally, the emerging themes were identified through narrative coding, which were then subsumed under categories and elaborated on in the section of "results."

\section{Credibility}

Conle (2000), in constructing "some criteria that would keep narrative inquiry within the bounds of rationality and not conflate it with fictional narrative," provided concrete guidelines by drawing on Habermas's four validity claims. He asserted that narrative inquirers should claim that

- they truthfully represent their feelings, intentions, etc;

- their stories are socially acceptable;

- the contents of the narratives are true with regard to what they describe;

- the language is comprehensible (Conle, 2000, p. 56).

All the four criteria served as guidance in enhancing the rigor of this narrative inquiry.

During the interviews, I tried to let the interviewees take the lead while I sought for clarification and expansion of what the interviewees said. Immediately after each interview was transcribed and translated, I read through it over and over again to ascertain whether there were any confusing points or eminent points needing further clarification through follow-up emails or additional face-to-face communication. Additionally, to check for researcher bias and partiality, the observation fieldnotes and interview transcripts were sent to the participants in order to confirm or disconfirm the authenticity of the content and render it as close as possible to the meanings indicated by the participants. Member checking was also used to verify the meanings drawn by myself against the perspectives of colleagues. Throughout the inquiry, I constantly shared my writing on a work-in-progress basis with the participants as well as "the response communities" by asking them to read my work and responding in ways that helped me discover other meanings that might lead to further retelling (Clandinin \& Connelly, 2000, p. 60). All these efforts contributed to ensuring the credibility of the study. 


\section{FINDINGS}

\section{Curriculum Model}

"Dual language programs vary considerably in the amount of time spent for instruction in each language and which subjects are taught in which languages" (Wright, 2015, p. 101). At this school, students start with the 50/50 model from Pre-K, which means 50\% of the instruction is in Chinese and the remaining 50\% is in English. The researchers and practitioners who developed the idea of dual language programs advocated a rigid separation of the two languages for instruction. In this program, the Chinese-side teachers teach Chinese Language Arts, as well as Math and Science in Chinese. English-side teachers are responsible for English Language Arts, Social Studies, and Math and Science English reinforcement. The teachers are native speakers of each language, and students swap midway through the day.

Sharing equal teaching responsibilities for the students, teachers on both sides in the same grade level have joint planning time on a weekly basis. They coordinate the curriculum closely in order to provide for content reinforcement without repetition in any language. Content-area instruction is taught in sheltered English and in a sheltered version of Chinese, for the purpose of making instruction comprehensible for the non-native speakers of the two languages. This practice is based on the premise that language is best learned when it is taught as "comprehensible input" (Krashen, 1985). To ensure teachers have the skills necessary to implement the best practices, the school regularly sends teachers to rigorous training in sheltered instruction and foreign language teacher development.

In this program, the foreign language, "Chinese" in this case, is not taught as an isolated subject matter. The aspects of language development do not take place in isolation, but in a context in which the teaching of Chinese is integrated with academic content and uses all language modes (reading, writing, speaking, and listening). The content teaching using the two languages is very effective for teaching both English and Chinese when delivered by trained teachers in second language acquisition and sheltered instruction who clearly have both language and content objectives in each lesson.

An important end goal of this school is for students to graduate high school with course credit to approximate a Minor in Chinese Language. To attain this goal, the school is committed to designing the entire curriculum to help students obtain advanced-level Chinese proficiency by the $8^{\text {th }}$ grade, and become prepared for Chinese AP classes in the $9^{\text {th }}$ grade. In this process, the school administration has reached a consensus on maintaining the integrity of the 50/50 immersion model throughout the curriculum so as to allow the benefits of two-way programs to fully play out.

\section{Chinese Language Proficiency and Literacy}

This research reveals a finding that has been repeatedly supported by previous research studies: When second language acquisition occurs in early childhood, students develop their language proficiency rapidly (Ovando \& Combs, 2012; Patricia, 2010; Peregoy \& Boyle, 2017; Wright, 2015). In this study, students have acquired Chinese language proficiency and literacy remarkably. According to the benchmark established by the school to gauge students' Chinese learning outcome, students are assessed in the beginning, mid-year, and end of year. The Principal Mr. Chuang proudly announced that " $85 \%$ of students achieved $75 \%$ in the first try. All students except two passed in the second try. So students are meeting our expectations."

The school started measuring students' reading ability with 100-200 high frequency Chinese characters covered by the textbook. It is found that students have gained a great success in character recognition. From there they introduced CCCC (Children's Chinese Competency Certification) to assess students' Chinese proficiency level in the domain of listening and reading. Starting in 2015, the school has begun to refine their benchmark further by adopting the Assessment of Performance toward Proficiency in Languages (AAPPL) test which follows the American Council on the Teaching of Foreign Languages (ACTFL) proficiency guidelines. The AAPPL test will allow students to perform tasks such as participating in a virtual video chat, creating wikis, e-mailing, and using apps to demonstrate language ability, and thus resulting in a more holistic understanding of students' Chinese proficiency in all four language domains.

Therefore, though the school has been around for only four years, students' Chinese proficiency and literacy have been closely monitored from the outset. Moreover, the assessment tools have been modified constantly to identify more effectively students' current level of Chinese development, so that teachers can adjust instruction accordingly and help students to progress further.

Accompanying the development of Chinese proficiency and literacy is students' appreciation of Chinese culture. Immersed in a culture-rich environment, students are engaged in various events and learning activities: learning Chinese proverbs during morning assembly, singing teacher-made Chinese songs connected to curriculum, learning about 12 Zodiac animals, celebrating Chinese New Year Festival and Mid-Autumn Festival, building sister school relationship with two elite elementary schools in China, exchanging greeting cards and letters with the students in sister schools, etc. These experiences have not only strengthened students' understanding about Chinese culture, but also cultivated a deeper respect for diversity. Students' increased multicultural perspective and competence will undoubtedly give them an edge in today's globalized and pluralistic world.

\section{Student Performance on State Standardized Tests}

Students in this school have demonstrated higher performance in State testing compared with their monolingual peers in regular schools. Table 2 extracted from 2014-15 State Academic Performance Report reflects the academic achievements made by the 3rd and 4th grade students in the program (The program was up to the 4th grade in 20142015 year.). 
TABLE 2

StATE ACAdEMic PeRformance Report 2014-15 CAMPUS PERFORMANCE

\begin{tabular}{|c|c|c|c|c|c|c|c|c|c|c|c|c|c|c|}
\hline & & State & District & Campus & $\begin{array}{r}\text { Afican } \\
\text { American }\end{array}$ & Hispanic & White & $\begin{array}{r}\text { American } \\
\text { Indian }\end{array}$ & Asian & $\begin{array}{r}\text { Pacific } \\
\text { Islander }\end{array}$ & $\begin{array}{l}\text { Two or } \\
\text { More } \\
\text { Races } \\
\end{array}$ & $\begin{array}{r}\text { Special } \\
\text { Ed } \\
\end{array}$ & $\begin{array}{r}\text { Econ } \\
\text { Disadv }\end{array}$ & ELLA \\
\hline \multicolumn{15}{|c|}{$\begin{array}{l}\text { STAARP Percent at Phase-in Satisfactory Standard or Above } \\
\text { Grade } 3\end{array}$} \\
\hline Reading & 2015 & $77 \%$ & $71 \%$ & $95 \%$ & ' & $93 \%$ & $100 \%$ & $\cdot$ & $100 \%$ & . & . & ' & $93 \%$ & , \\
\hline \multicolumn{15}{|c|}{$\begin{array}{l}\text { STAAR Percent at Phase-in Satisfactory Standard or Above } \\
\text { Grade } 4\end{array}$} \\
\hline Reading & 2015 & $74 \%$ & $64 \%$ & $95 \%$ & $78 \%$ & $100 \%$ & $100 \%$ & $\cdot$ & $100 \%$ & . & ' & ' & $80 \%$ & , \\
\hline Witing & 2015 & $70 \%$ & $64 \%$ & $88 \%$ & $78 \%$ & $80 \%$ & $100 \%$ & . & $100 \%$ & . & ' & ' & $80 \%$ & ' \\
\hline
\end{tabular}

It shows that $95 \%$ of the 3rd Grade students passed Reading test in comparison with $71 \%$ district and $77 \%$ state rate. In terms of the 4th Grade student performance, 95\% passed Reading and 88\% passed Writing, both far higher than the district and state rates too. Additionally, what is worth special mentioning is that Mr. Chuang disclosed that the school ranked 5th in reading and 9th in Math among approximately 170 elementary schools in the school district in the State Standardized Tests in 2014-2015.

The school continued to progress steadily in the State Standardized Tests in 2015-2016 as table 3 indicates. Student results across grades and subjects are all well above the district and state rates.

TABLE 3

STATE ACADEMIC PERFORMANCE REPORT 2015-16 CAMPUS PERFORMANCE

\begin{tabular}{|c|c|c|c|c|c|c|c|c|c|c|c|c|c|c|}
\hline \multicolumn{15}{|c|}{ 2015-16 CAMPUS PERFORMANCE } \\
\hline & & State & District & \multicolumn{3}{|c|}{ African } & \multicolumn{2}{|r|}{ American } & Asian & $\begin{array}{r}\text { Pacific } \\
\text { Islander }\end{array}$ & $\begin{array}{l}\text { More } \\
\text { Races }\end{array}$ & $\begin{array}{r}\text { Special } \\
\text { Ed }\end{array}$ & $\begin{array}{l}\text { Econ } \\
\text { Disadv }\end{array}$ & ELA^ \\
\hline \multicolumn{15}{|c|}{$\begin{array}{l}\text { STAARPercent at Level II Satstactory Standard or Above } \\
\text { Grade } 3\end{array}$} \\
\hline Rexling & 2016 & $73 \%$ & $67 \%$ & $91 \%$ & $84 \%$ & $86 \%$ & $89 \%$ & $\cdot$ & $100 \%$ & $\cdot$ & $100 \%$ & ' & $89 \%$ & $90 \%$ \\
\hline Mathematics & 2016 & $75 \%$ & $70 \%$ & $93 \%$ & $84 \%$ & $79 \%$ & $100 \%$ & . & $100 \%$ & . & $100 \%$ & ' & $79 \%$ & $80 \%$ \\
\hline \multicolumn{15}{|c|}{$\begin{array}{l}\text { STAARPercent at Level II Satisfactory Standard or Above } \\
\text { Grade } 4\end{array}$} \\
\hline Reading & 2016 & $75 \%$ & $69 \%$ & $88 \%$ & ' & $67 \%$ & $100 \%$ & . & $100 \%$ & . & ' & ' & $82 \%$ & " \\
\hline Mathematcs & 2016 & $73 \%$ & $70 \%$ & $98 \%$ & , & $92 \%$ & $100 \%$ & . & $100 \%$ & . & ' & ' & $100 \%$ & , \\
\hline Writing & 2016 & $69 \%$ & $64 \%$ & $86 \%$ & , & $67 \%$ & $93 \%$ & . & $100 \%$ & . & , & , & $91 \%$ & , \\
\hline
\end{tabular}

\begin{tabular}{|c|c|c|c|c|c|c|c|c|}
\hline \multicolumn{9}{|c|}{$\begin{array}{l}\text { STAARPercent at Level II Satisfactory Standard or Above } \\
\text { Grade } 5^{*}\end{array}$} \\
\hline Reading & 2016 & $81 \%$ & $73 \%$ & 95\% & $88 \%$ & $100 \%$ & $100 \%$ & . \\
\hline Mathematics & 2016 & $86 \%$ & $80 \%$ & 95\% & $88 \%$ & $100 \%$ & $100 \%$ & . \\
\hline Science & 2016 & $74 \%$ & $68 \%$ & $92 \%$ & $28 \%$ & $100 \%$ & $100 \%$ & . \\
\hline
\end{tabular}

These data compellingly unfold that children in a bilingual education program have not only developed their proficiency in a second language but also outperformed their monolingual peers in English and academic content.

Another academic achievement manifested in Table 4 displays that students in 2014-2015 had a 10\% increase in total pass rate in both Reading and Math than 2013-2014. The Assistant Principal Mr. Reid added that in 13-14 18\% of the students were at the advanced level in reading and in 2014-2015 40\% were identified at the advanced level. When accounting for the improvement, he drew on the research that suggests that there can be a lag in language students comparing to their peers at the beginning, but by the second school year when the dual language benefits kick in students will exhibit equal or better performance than their peers.

While interpreting student performance on the Standardized Tests, Mr. Reid made another good point, In 2014-15, students have only been in the program for two years. They started as 2nd graders, then 3rd graders, then they had one more year, then they took the test. It's going to be different from students who started in PreK or K. By the time these students are tested in their fourth or fifth year in dual language program, hopefully it will show more impact. (Mr. Reid, Associate Principal) 
Researchers found little difference between programs in the very early grades. "It was not until the content became more demanding in the later grades that difference among programs became significant" (Richard-Amato, 2010, p. 425). The longer students are in a dual language program, the greater academic achievements they tend to demonstrate comparing with the students in regular education programs. This study has presented a powerful counterargument to the prevalent misconception among the public that bilingual education impedes English language acquisition and academic achievement.

TABLE 4

STUDENTS _\% SATISFACTORY ON STAAR

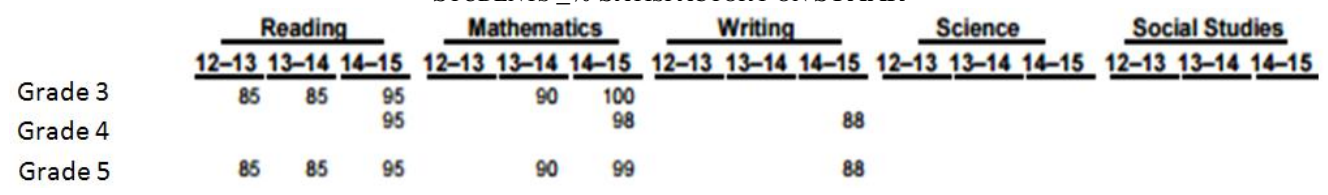

A Balanced Chinese-English Dual Language Curriculum

As the first school-wide mandarin immersion program in the State, in the circumstances that there is a scarcity of resources and materials, the school has successfully established a balanced Chinese-English dual language curriculum. Beginning in pre-Kindergarten, all students spend 50\% of the instructional day in a Mandarin class and the remaining $50 \%$ in an English class, swapping midway through the day. As in other bilingual programs, it uses one language for one set of subjects and the other language for a separate set. Every curriculum area develops language competence. All subject areas contribute to the growth of children's language, and likewise, the acquisition of language promotes the mastery of subject areas. The teachers are native speakers of each language, and can fully understand children speaking one language but speak to them almost entirely in the other language. Both sets of teachers serve as important language models for children, identifying the language skills that need to be improved in both languages.

Enacting a balanced approach to curriculum, the school has not only developed students' Chinese proficiency and taught academic content in Chinese, but also made every effort to "push the rigor on the English side," to quote Mr. Reid. He termed this approach "a balanced literacy pedagogy," in which, students' English proficiency is never let fall between the cracks. Students receive differentiated reading instruction that allows them to read at their own level and well-structured reading and writing workshop where students' English reading and writing get addressed to the fullest possible degree.

As stated on the school website, it "prepare(s) students for the rigorous STAAR test..." while also "charged with the same mission to educate children in all the TEKS (administered only in English) necessary to be college and careerready." Following a balanced dual language curriculum, the school has indeed achieved this goal. Currently, the school administrators are planning to adopt a new Chinese literacy curriculum that helps students to read at a higher level and place more emphasis on English writing skills. When asked to name one most desired advancement the program can make in the future, Mr. Chuang responded the following, "I hope students will become balanced bilingual, and do equally well in English and Chinese. When they reach the 8th grade, they can be AP ready, and move forward from there. This is my goal." It can be foreseen that if students keep making the same strides, the goal will be reached beyond any doubt in the near future.

\section{A Positive School Environment}

Key to the success of this program is an affirming sociocultural environment, which is most likely to occur in twoway and foreign language immersion programs. The two languages are given equal status, thus creating self-confidence among all students. For Chinese-speaking students, this program functions as a developmental bilingual model that helps them to maintain their home language and develop a positive sense of their cultural heritage and ethnolinguistic identities. For native-English-speaking students, the program functions as a foreign language immersion model that enables them to have an academically and personally enriching experience of being exposed to different languages and cultures.

When instruction is in Chinese, the English speakers must seek help from their Chinese-speaking peers, just as the Chinese-speaking students must count on the English speakers when instruction is in English. Language majority and minority students "play a mutually important role with each other as linguistic and sociocultural models" (TESOL, 1993, p.1) Both thrown into a language they are not familiar with, they experience the same frustration and uncertainty, and share a strong desire to learn, therefore tend to better understand and accommodate each other, their language, and culture. In two-way bilingual programs, "accommodation is no longer a one-way street, with the language minority students doing all the adjusting” (Richard-Amato, 2010, p. 425). Both language-majority and language-minority students affirm and respect their language learning counterparts more. All these factors contribute to high student selfesteem found in this program. A similar affective advantage was also "found in the Spanish/English two-way language in Valley Center, California, and the Cantonese/English two-way language program in lower Manhattan" (RichardAmato, 2010, p. 424).

Not only a positive relationship between students is clearly displayed, a close bond is also established between parents and the school. The parents have been instrumental in promoting and advancing this program. Recognizing that the immersion experience is not only new for students, but for parents as well, the school has regular parent meetings 
and trainings. The parents are advised on how to help their children through an initial period of frustration and discomfort when exposed to an unfamiliar environment, how to facilitate their children's acquisition of Chinese more effectively, and many other important issues. Additionally, the school offers a free Rosetta Stone license to parents who want to learn Chinese, and after-school conversational classes for parents who are interested in learning alongside their children. With continued support both at home and at school, students flourish linguistically, academically, cognitively, and socioculturally.

\section{DISCUSSION}

Evidence in this study has overwhelmingly indicated that students participating in this program benefit from becoming proficient in two languages and are not at a disadvantage academically by learning content through another language. Young children are remarkably adaptive, with the cognitive and linguistic capacity to pick up a foreign language quickly. When spending a large percentage of their day immersed in a foreign language, they adapt to the language and culture and begin using the language comfortably in classroom and social situations. Moreover, the bilingual students develop cognitive and academic advantages over, and outperform, monolinguals on standardized tests. As students learn the content in both Chinese and English simultaneously and learn to read and write in both languages, their linguistic and academic needs are both met adeptly.

There are many factors that have contributed to the success of this Chinese-English bilingual program. First and foremost, the school curriculum characterized by two-way and foreign language immersion provides students with access to the core curriculum, development of both languages, and opportunities for classroom interaction. Researchers have persuasively suggested that language instruction is best delivered through context-embedded experience. In other words, the content-area study provides an optimal context for second language acquisition to happen. This curriculum model is more effective than foreign language programs in which students are involved in the target language as a subject matter for only a small portion each day/week.

Sociocultural and affective factors such as high levels of students' self-esteem and parent involvement is another essential element in this program's success. It enriches students' sociocultural experiences and raises personal satisfaction in both language majority and minority students. This program has helped change the view of bilingual education as a remedial program to being viewed as an enrichment program. It has also underscored the growing importance of seeing bilingual education as a national resource of all students. Just as Richard-Amato (2010) proclaimed, "Bilingualism is an appropriate goal not only for our schools, but for our country as a whole," and "this goal becomes more and more critical as our nation becomes increasingly more diverse"(p. 429).

\section{CONCLUDING REMARKS}

This study brings to light an important implication that an effective bilingual education program develops students' language and literacy proficiency, leads them in successful academic achievement, and nurtures sociocultural integration. Influenced by the current educational policies, bilingual education has been marginalized to a great extent due to the high stakes attached to English language achievement tests. Consequently, more and more school districts across the country have phased out bilingual education in the false hope that this will speed up English acquisition. This research study offers a compelling case that children in bilingual programs consistently outperform those in all-English programs on standardized tests. Bilingual education does not hinder students' English language acquisition. Instead, it accelerates students' English proficiency development while promoting students' second language acquisition and overall academic achievements.

\section{REFERENCES}

[1] Clandinin, D. J., \& Connelly, F. M. (1994). Personal experience methods. In N. K. Denzin, \& Y. S. Lincoln (Eds.), Handbook of qualitative research (pp. 413-227). Thousand Oaks, CA: Sage.

[2] Clandinin, D. J., \& Connelly, F. M. (2000). Narrative inquiry: Experience and story in qualitative research. San Francisco, CA: Jossey-Bass.

[3] Clandinin, D. J., Pushor, D., \& Orr, A. M. (2007). Navigating sites for narrative inquiry. Journal of Teacher Education, 58(1), 21-35.

[4] Conle, C. (2000). Narrative inquiry: Research tool and medium for professional development. European Journal of Teacher Education, 23(1), 49-63.

[5] Connelly, F. M., \& Clandinin, D. J. (1990). Stories of experience and narrative inquiry. Educational Researcher, $19(5), 2-14$.

[6] Cummins, J. (1999). Alternative paradigms in bilingual education research: Does theory have a place? Educational Researcher, 28(7), 26-32.

[7] Freemark, S., \& Smith, S. (2014, August 18). This is your brain on language. Retrieved July 3, 2017, from http://www.americanradioworks.org/segments/this-is-your-brain-on-language/.

[8] Krashen, S. (1985). The input hypothesis: Issues and implications. London: Longman.

[9] Noack, R. (2015, September 24). The future of language. Retrieved July 3, 2017, from https://www.washingtonpost.com/news/worldviews/wp/2015/09/24/the-future-of-language/?utm_term=.7eec00c3322b. 
[10] Ovando, J., \& Combs, M. C. (2012). Bilingual and ESL classrooms: Teaching in multicultural contexts (5th ed.). McGraw-Hill Higher Education.

[11] Peregoy, S., \& Boyle, O. (2017). Reading and writing, and learning in ESL: A resource book for teaching K-12 English learners ( $7^{\text {th }}$ ed.). NJ: Pearson Education.

[12] Richard-Amato, P. A. (2010). Making it happen: From interactive to participatory language teaching--Evolving theory and practice $\left(4^{\text {th }}\right.$ ed.). NY: Pearson Education.

[13] Teachers of English to Speakers of Other Languages. (1993). Bilingual basics: The official publication of the bilingual interest section, TESOL. Alexandria, VA.

[14] Tinajero, J. (2005). Bilingual education in Texas: Lighting the path, leading the way. Language Learner, November/December, 17-20.

[15] Wright, W. E. (2015). Foundations for teaching English Language Learners: Research, theory, policy and practice (2 ${ }^{\text {nd }}$ ed.). Philadelphia, PA: Caslon Publishing.

Liping Wei is an Assistant Professor in the School of Education, Health Professions, and Human Development at the University of Houston-Victoria. She specializes in ESL/TESOL teacher preparation and development. 